\title{
Employees' work engagement in a railway organisation: A perspective of ethical work climate and leadership behaviour
}

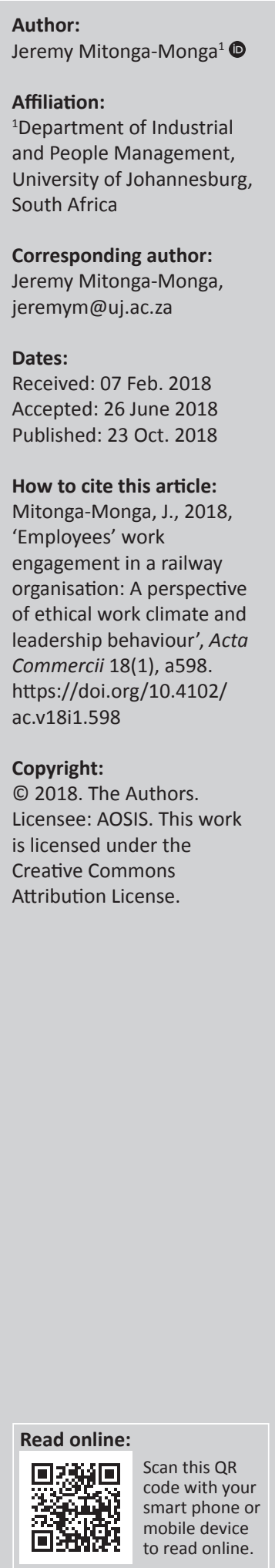

Orientation: Understanding the factors that influence employee performance and well-being is a crucial issue because it can not only create a positive working environment but also promote competitive advantage for the organisation.

Research purpose: To investigate the effect of ethical work climate and ethical leadership behaviour on work engagement of employees.

Motivation for the study: Organisations are facing difficulties in improving organisational performance and workers' well-being because of unethical behaviour and lack of accountability. This study aims to provide insight into suggested factors that might positively affect employee performance and well-being.

Research design, approach and method: A quantitative research design following a crosssectional research design was employed. A sample of 839 employees in a railway organisation in the Democratic Republic of Congo completed the Ethical Climate Questionnaire, the Ethical Leadership Work Questionnaire and the Utrecht Work Engagement Scale. Hierarchical regression was applied to identify the effect of ethical work climate and ethical leadership behaviour on the level of work engagement of employees.

Main findings: The findings indicate that ethical work climate and ethical leadership behaviour positively and significantly predict the level of employees' work engagement.

Practical/managerial implications: Developing ethical leaders and finding creative ways to teach and enforce ethical conduct and policies to facilitate workplace fairness will improve the well-being of employees.

Contributions/value-add: The study contributes to employee engagement theory by suggesting that experiences and perceptions of a positive ethical work climate and ethical leadership behaviour contribute to a high level of psychological attachment and well-being of employees.

\section{Introduction}

The past three decades have seen a growing interest in exploring the link between ethical behaviour and employee's work engagement (WE) (Chughtai, Byrne \& Flood 2015:652). Ethical behaviour is defined as an act or a behaviour that directs people to understand what is right or wrong (Thaw, Dominic \& Mahmood 2012) and that is intended to produce kind and/or fair outcomes (Schulman 2002). Work engagement is defined as 'a positive, affective, psychological work-related state of mind that leads employees to actively invest themselves emotionally, cognitively and physically in their work' (Schaufeli et al. 2002:74). This construct has been found to be positively related to various organisational measures of performance (Rich, Lepine \& Crawford 2010:617). In light of evidence suggesting that more than $70 \%$ of employees are not engaged (Gallup Employee Engagement Survey 2010), in order to increase organisational performance and improve health and well-being, there is a need to understand both in practice and in theory how and why individuals become engaged in their work (Akhtar et al. 2015:45; Schaufeli 2013:174). For instance, Lu, Xie and Guo (2018:186) urge researchers to closely scrutinise antecedents such as ethical behaviour and leadership in order to understand why some individuals engage closely with their work tasks. In this context, Obicci (2015:40) notes that a positive and ethical work environment and good leadership ethics are considered to be key factors exerting a profound influence on employee loyalty and well-being. However, understanding how individuals engage and perform in different kinds of organisational 
climates and under various leadership styles has been a point of contention among both researchers and scholars (Chughtai et al. 2015:650). Ethical work climate (EWC) refers to a group of prescriptive climates reflecting organisational procedures, policies and practices that have moral consequences (Victor \& Cullen 1988:101-103). Ethical leadership behaviour (ELB) refers to conduct that is consistent with acceptable norms and demonstrated through leaders' actions and relationships (Brown \& Treviño 2014; Brown, Treviño \& Harrison 2005; Kalshoven, Den Hartog \& De Hoogh 2013).

Ethical work climate refers to shared perceptions by employees of appropriate workplace and role conduct (Mitonga-Monga 2018). Ethical leadership behaviour refers as sets of universal values such as reliability, impartiality and justice (Obicci 2015). Several lines of arguments and researches have suggested that EWC and ELB relate to a number of work-related outcomes, such as job satisfaction (Bedi, Alpaslan \& Green 2015:2), commitment (MitongaMonga \& Cilliers 2016:35), ethical behaviour ( $\mathrm{Tu}, \mathrm{Lu} \& \mathrm{Yu}$ 2017:229), willingness to report problems to a supervisor, extra-role behaviour and employee well-being (MitongaMonga \& Cilliers 2015:242; Mitonga-Monga, Flotman \& Cilliers 2016:327). Although previous studies have established that EWC and ethical leadership are associated with various positive outcomes (Mitonga-Monga \& Flotman 2017:326; Treviño, Den Nieuwenboer \& Kish-Gephart 2014:635; Yener, Yaldiran \& Ergun 2012:727), there seem to be a paucity of research examining the effects of EWC and ELB on employee well-being. Understanding whether or not these variables influence an employee's WE will potentially advance the researcher's theoretical understanding of employees' psychological attachment to the organisation and enhance his ability to offer recommendations to human resource practitioners who are seeking to promote employees' wellbeing in the Democratic Republic of Congo (DRC) work context.

\section{Democratic Republic of Congo work context}

The DRC, like other African countries, is facing political, economic and social problems associated with political conflict, hyperinflation, corruption and unethical behaviour (Mitonga-Monga \& Cilliers 2015:243). These problems have been exerting a negative effect on the economic growth of the country for several decades (Mitonga-Monga \& Flotman 2017:272). Currently, the DRC government is making a concerted effort to speed up institutional, infrastructural, economic and social reforms to ensure growth and reduce the high levels of corruption and impunity (Mitonga-Monga \& Cilliers 2016:37). To achieve growth in this turbulent context and remain competitive, both public and private industries are urged to use efficiently their resources and skills at their disposal. Unfortunately, most of the organisations in the DRC are characterised by a lack of skilled workforce, mismanagement and inefficient use of resources
(Mitonga-Monga \& Cilliers 2015:246). In-depth analysis conducted among nongovernmental organisations (NGOs) and the African Development Report 2015 have revealed that the unstable political climate and corruption have resulted in talented and highly skilled employees leaving the DRC with the objective of seeking better job prospects in other countries. This may impede the performance of public and private organisations and could slow economic growth. Therefore, knowledge of the factors that help to boost the performance and psychological well-being of employees is considered important. Moreover, ethical leadership that will improve our understanding of employee behaviour and create an appropriate and favourable ethical working climate aimed at enhancing employee's WE and well-being in the railway industry in particular is scarce.

\section{Conceptual perspectives}

The EWC model developed by Victor and Cullen (1988:101125), the Ethical Leader Behaviour Model (Kalshoven, Den Hartog \& De Hoogh 2011:52) and the Utrecht Work Engagement Model (Schaufeli et al. 2002:71) provide the conceptual and empirical framework for this study.

\section{Ethical work climate}

Ethical work climate can be described as shared formal and informal conditions influencing employees' response to policies, procedures and practices with moral consequences (Martin \& Cullen 2006:293; Mitonga-Monga \& Cilliers 2015:242; Treviño et al. 2014:635; Victor \& Cullen 1988:104). Such a climate arises when employees are confident that certain forms of ethical reasoning and behaviour constitute expected standards or norms for decision-making within the organisation. Literature indicates that the key aspects of EWC include the following: (1) Caring, which refers to the perception that decisions are and should be based on an overarching concern for the well-being of others; (2) Law and codes, which refer to the perception that the organisation supports principled decision-making based on external codes, such as the law and professional codes of conduct; (3) Rules, which refer to the extent to which decisions are perceived to be guided by a strong, pervasive set of local rules or standards, such as a code of conduct; (4) Independence, which refers to the extent to which individuals believe that they should act according to their personal moral convictions to make ethical decisions; (5) Instrumental, which refers to the extent to which individuals look out for their own self-interest, first and foremost, to the exclusion of the interests of others (Mitonga-Monga 2018:15). The effect of perceptions relating to EWC on the WE of employees is of significant interest to researchers (Yener et al. 2012; Mitonga-Monga \& Cilliers 2015:243). Researchers in the business ethics field commonly hypothesise that higher levels of employee engagement and psychological well-being will be present when employees consider there to be a strong and positive EWC (MitongaMonga \& Cilliers 2015:243). 


\section{Ethical leadership behaviour}

Kalshoven et al. (2013:212) argue that ELB largely influences employees' behaviour and attitudes by establishing ethical standards and communicating them to employees. Leaders display ethical behaviour when their decisions are made for altruistic reasons, rather than being driven by self-interest (Brown et al. 2005:121; Kacmar et al. 2013:33). Ethical leadership behaviour refers to the extent to which individual leaders feel a responsibility to do what is right and honest; align themselves with moral principles and values; act with fairness, respect and integrity; make principled choices and refrain from showing preferential treatment; guide employees and clarify their responsibilities so that employees understand what is expected of them; emphasise ethical norms; and communicate expectations regarding ethical behaviour (De Hoogh \& Den Hartog 2008:298; Eisenbeiß \& Brodbeck 2014:343; Kalshoven et al. 2011).

Brown et al. (2005) define ELB as the demonstration of normatively appropriate conduct through personal actions and interpersonal relationships, and promotion of such conduct to followers through two-way communication, reinforcement, and decision-making'. Literature outlines key components of ELB as follows: (1) Fairness, which refers to the extent to which ethical leaders act with integrity and treat employees fairly, make principled and fair choices, are trustworthy and honest, do not practise favouritism and take responsibility for their own actions; (2) Power sharing, which is the extent to which ethical leaders involve their employees in the decision-making process and listen to their ideas and concerns, allowing employees to have more control and be less dependent on the leaders; (3) Role clarification, which refers to the extent to which ethical leaders act in a transparent manner and engage in open communication, clarifying responsibilities, performance goals and expectations for employees; (4) People orientation, which refers to the extent to which ethical leaders demonstrate genuine caring behaviour, treating others with respect and dignity and providing support, and ensuring that their needs are met; (5) Ethical guidance, which refers to the extent to which ethical leaders convey standards regarding ethical conduct and set rules and codes of conduct which provide guardrails or guidelines for ethical behaviour; (6) Concern for sustainability, which refers to the extent to which ethical leaders are aware of their impact on stakeholders and society. It also refers to the extent to which ethical leaders take responsibility for protecting and promoting the interests of stakeholders; (7) Integrity, which refers to the extent to which ethical leaders align what they say with what they do, whether they keep promises, whether they behave in a consistent manner and whether they are trusted and believed (Kalshoven et al. (2011:52). Work environments in which there are strong and positive ethical leaders are likely to be characterised by norms and policies that value and reward ethical conduct (Den Hartog \& Belschak 2012:35). Leaders who demonstrate positive ethical behaviour tend to hold workers accountable, and use discipline and punishment accordingly. Conversely, leaders who refrain from punishing unethical behaviour and apply rewards inconsistently may promote a work environment where employees will demonstrate a low level of engagement.

\section{Work engagement}

Researchers in the field of ethical behaviour consider EWC and ELB to be critical determinants of employee engagement (Chughtai et al. 2015:655; Rich et al. 2010:617). If EWC and ELB are considered to be organisational resources, they can be predictors of the level of employees' WE. For this reason, it is possible to link EWC and ELB to WE. Work engagement is considered to be a positive, fulfilling, work-related state of mind that is characterised by various key aspects, such as vigour, dedication and absorption: (1) Vigour refers to willingness to invest effort in one's work. This component is characterised by a high level of energy and mental resilience and persistence, even in the face of adversity. (2) Dedication refers to being fully involved in one's work and experiencing a sense of significance, enthusiasm, inspiration, pride and challenge. (3) Absorption refers to a person concentrating fully on and being happily engrossed in his or her work, to the extent that time seems to pass quickly and he or she experiences difficulty in detaching from this work. Engaged employees tend to feel vigorous and strong and be enthusiastic about their work, and are largely immersed in their work activities. Engaged employers tend to be dedicated and psychologically connected if their leader is ethical and shows concern for others, and demonstrates fairness and integrity. Research has established that high levels of WE can lead to valued outcomes such as job satisfaction ( $\mathrm{Lu}$ et al. 2018:186; Saks 2006:600), improved health and well-being (Halbesleben 2010:201; Schaufeli, Bakker \& Van Rhenen 2009:893; Schaufeli 2013:16), reduced turnover and lower absenteeism (Lee \& Ok 2015:84), as well as enhanced performance (Rich et al. 2010:617).

\section{Ethical work climate and ethical leadership behaviour as predictors of work engagement}

Employees will be motivated to engage and perform when they are committed to their work, happy in their jobs and prepared to go the extra mile. According to Engelbrecht, Heine and Mahembe (2014:2), WE occurs when individuals have the ability, motivation, autonomy and knowledge to engage. EWC as an organisational resource contains elements that can influence WE (see Mitonga-Monga \& Cilliers 2015:242; Yener et al. 2014:724). Firstly, employees have the ability to engage in their job when the organisation provides positive and clear policies, procedures and practices (indicative of a positive, EWC), as well as a supporting structure that contributes to employees' ability to perform better (Lee \& Ok 2015:84). Ethical work climate is one which reflects an organisation's resources, processes, procedures, policies and practices, with moral consequences that may help employees in the execution of their daily work. According to DeConinck (2010:1349), these organisational resources are associated with WE because they provide employees with a positive perception of a 
psychologically healthy and meaningful working environment. It can thus be proposed that an employee's positive perception of EWC contributes positively to his or her WE or psychological well-being.

Secondly, individuals will be encouraged to be engaged with and perform well in their work when they are treated with integrity, respect and fairness, and are valued by the organisation (Demirtas et al. 2017:183; Hassan \& Ahmed 2011:164; Kalshoven et al. 2013:211; Lu \& Lin 2014:209; Mayer, Kuenzi \& Greenbaum 2010:8). According to Kalshoven et al. (2013:213) and Mayer et al. (2013:90), the behaviour of ethical leaders leads to employee engagement, as well as attitudinal and motivational well-being and performance-related outcomes, because employees are consulted, treated fairly, and experience care and support, which leads to a positive job attitude and constructive ethical behaviour. Highly engaged employees will be more motivated, encouraged and willing to put in extra effort, because they are more committed to delivering high-quality work performance (Babin, Boles \& Robin 2000:346; DeConinck 2010:345).

Den Hartog and Belschak (2012:41) found ethical leadership to be a positive predictor of employees' WE and argue that emphasis on shared moral values and the honesty, care, fairness, power sharing and role clarification modelled by ethical leaders will enhance employees' WE and performance. In other words, employees tend to be engaged in their work when they perceive their leaders to be ethical and honest. The biographical characteristics of age, gender, education and tenure were found to be related to employees' level of engagement (Changsuk et al. 2018:104; James, McKechnie \& Swanberg 2011:178). This implies that older employees with a high level of education and experience seem to exhibit a higher level of engagement than younger employees. It can therefore be proposed that ELB has a positive influence on employees' WE. Although research provides evidence of how EWC and ELB predict employees' level of engagement and performance, the extent to which these influences are sustained in a developing country work setting, such as the DRC, is as yet unknown.

\section{Goal of the study}

The objective of the study was to determine whether or not EWC and ELB influence employees' level of WE in a railway organisation in the DRC. The following research question was formulated: Do employees' perceptions of EWC and ELB influence their levels of WE? The outcome of this study could potentially contribute to future human resource interventions with regard to promoting employees' level of engagement, well-being and performance. It is believed that such interventions will be successful in an environment where leaders create a positive and ethical work atmosphere, and act and treat others in an ethical manner (MitongaMonga \& Cilliers 2016:35).

\section{Method \\ Participants and setting}

The participants were 2500 employees of a DRC railway organisation, who were purposively selected. Only 839 questionnaires were collected, yielding a final sample of $n=839$ (response rate $=36 \%$ ). The participants were permanently employed and the majority were men (68\%) in the establishment stage of their careers (24-40 years: 63\%), with a university degree (38\%) and tenure in the organisation (31\%).

\section{Procedures}

Participants were invited to participate voluntarily in the study. The researcher respected their anonymity and confidentiality at all times. The participants received a sealed envelope that included an invitation letter, management approval to conduct the study and a participant informed consent form.

\section{Measuring instruments}

Participating employees were asked to complete the selfreport survey on EWC, ELB and WE. These instruments are described below.

\section{Ethical leadership behaviour}

Ethical leadership behaviour (independent or predictor variable) was assessed using the Ethical Leaders' Work Questionnaire (ELWQ: Kalshoven et al. 2011:51). In keeping with the observation by Kalshoven et al. (2011:52-54) that subordinates are best equipped to assess the behaviour of leaders, the researcher asked participants to rate their leaders on the 38 items contained in the questionnaire. These items included the following: 'Holds me responsible for work that I have no control over'; 'Is interested in how I feel and how I am doing'; 'Allows subordinates to influence critical decisions'; 'Shows concern for sustainability issues'; 'Clearly explains integrity-related codes of conduct'; 'Explains what is expected of each group member'; 'Can be trusted to do the things he/she says'. The ELWQ utilises a 5-point scale for responses, where $1=$ strongly disagree and $5=$ strongly agree. Internal consistency reliabilities ranging from 0.84 to 0.90 have been reported for the scale (Kalshoven et al. 2011:68). In the context of this study, internal consistency reliability coefficients ranging from 0.70 to 0.95 were reported for this scale.

\section{Ethical work climate}

Ethical work climate (independent or predictor variable) was measured using the Ethical Climate Questionnaire (ECQ: Victor \& Cullen 1988:101-125). The ECQ is a 26-item selfreporting instrument that measures caring, law and codes, rules, independence and instrumental climates. Items in the ECQ included the following: 'Employees strictly obey the company's policies'; 'Employees can decide for themselves what is right and wrong'; 'Employees are expected to strictly follow legal or professional standards'; 'What is best for 
everyone is the major consideration here'; 'Employees are working for their own interest'. The ECQ utilises a 5-point scale for responses, where $1=$ strongly disagree and $5=$ strongly agree. Victor and Cullen (1988:102-125) and Cullen, Victor and Bronson (1993:667-674) reported an internal consistency reliability of 0.76 to 0.89 for the scale. In this study, the scale obtained reliability coefficients ranging from 0.81 to 0.92 .

\section{Work engagement}

Work engagement (dependent or criterion variable) was measured by means of the Utrecht Work Engagement Scale (UWES: Schaufeli et al. 2002:71). The UWES is a 9-item scale used to measure an employee's vigour (e.g. 'At my work, I feel bursting with energy': 3 items), dedication (e.g. 'I am proud of the work that I do': 3 items) and absorption (e.g. 'It is difficult to detach myself from my job': 3 items). The instrument utilises a 6-point scale for responses, where $0=$ never and $6=$ every day. Internal consistency reliabilities ranging from 0.64 to 0.73 have been reported for the scale (Schaufeli, Bakker \& Salanova 2006:709). In terms of this study, the subscales obtained the following reliabilities: vigour (0.91), dedication (0.88) and absorption (0.91). The overall reliability of scores obtained from the scale was 0.94 .

\section{Data analysis}

The statistical analysis was carried out with the help of the Statistical Package for Social Sciences (SPSS), version 25 for Windows software (2018). Descriptive statistics, correlations and hierarchical multiple regressions were employed for data analysis. Correlational analysis was utilised to investigate the relationship between EWC and ELB as the independent variables, and $\mathrm{WE}$ as the dependent variable. In terms of statistical significance, it was decided to set a cut-off value at the $95 \%$ confidence level $(p \leq 0.05)$. Hierarchical multiple regression analyses were performed to determine whether or not EWC and ELB acted as significant predictors of the UWES variables. For the purpose of this study, $R^{2}$ values larger than 0.13 (medium effect) at $p \leq 0.05$ (Cohen 1992:155-156) were regarded as practically significant. Prior to conducting the various regression analyses, Harman's single-factor test was performed to ensure the absence of common method bias (using the cut-off point of eigenvalue $=$ $1 ; \sigma \leq 50)$. Collinearity diagnostics was examined to ensure that the zero-order correlations were below the level of concern $(r \geq 0.90)$, that the variance inflation factors did not exceed 10 and that the tolerance values were close to 1.0 (Hair et al. 2010:93-149).

\section{Ethical considerations}

Ethical clearance to conduct the research was obtained from the researcher's institution, while permission for the study was obtained from the management of the railway organisation in the Democratic Republic of Congo (No 11/40. A022/SD.Form/2013).

\section{Results}

Table 1 presents the means, standard deviations, Cronbach's alpha and correlations of the study variables, namely EWC, ELB and WE. In terms of the ECQ variables, instrumental obtained the highest mean score $(\operatorname{mean}[\mathrm{M}]=4.12$; standard deviation $[\mathrm{SD}]=0.61)$, followed by law and codes $(\mathrm{M}=4.08$; $\mathrm{SD}=0.64)$, total EWC $(\mathrm{M}=4.05 ; \mathrm{SD}=0.55)$, rules $(\mathrm{M}=4.03$; $\mathrm{SD}=0.66)$, caring $(\mathrm{M}=4.02 ; \mathrm{SD}=0.60)$ and independence $(\mathrm{M}=3.98$; $\mathrm{SD}=0.85)$. In terms of the ELWQ ELB variables, the sample overall scored the highest on ethical guidance $(\mathrm{M}=4.02 ; \mathrm{SD}=0.61)$, followed by power sharing $(\mathrm{M}=4.00$; $\mathrm{SD}=0.63)$, people orientation $(\mathrm{M}=3.99$; $\mathrm{SD}=0.63)$, role clarification $(\mathrm{M}=3.95 ; \mathrm{SD}=0.70)$, total ELB $(\mathrm{M}=3.95$; $\mathrm{SD}=0.65)$, integrity $(\mathrm{M}=3.93 ; \mathrm{SD}=0.86)$ and fairness $(\mathrm{M}=3.92 ; \mathrm{SD}=0.64)$. In terms of the UWES variables, vigour obtained the highest mean score $(\mathrm{M}=4.57$; $\mathrm{SD}=0.99)$, followed by dedication $(\mathrm{M}=4.47 ; \mathrm{SD}=0.92)$ and absorption $(\mathrm{M}=4.44 ; \mathrm{SD}=0.92)$. All three dimensions imply a relatively high level of WE within the sample. The participants scored relatively high on the demographic characteristics of tenure $(\mathrm{M}=0.57 ; \mathrm{SD}=0.50)$ and gender $(\mathrm{M}=0.31 ; \mathrm{SD}=0.46)$, and the lowest on age and education $(\mathrm{M}=0.12 ; \mathrm{SD}=0.32)$.

\section{Correlational analysis}

The significant relationships between the ECQ, ELWQ and UWES variables are reported in Table 1 . The results show that the EWC and ELB variables were significantly and positively related to the WE variables ( $r \geq 0.35$; medium practical effect size, to $r \geq 0.87$; large practical effect size). These results indicate that the zero-order correlations were well below the threshold level of concern $(\geq 0.90)$ about multicollinearity. Table 1 shows that the total people orientation, fairness, power sharing, concern for sustainability, ethical guidance, role clarification and integrity ELWQ variables and the total caring, law and codes, rules, independence and instrumental ECQ variables were positively and significantly related to the total vigour, dedication and absorption UWES variables ( $p$-values range between $p \leq 0.01$ and $p \leq 0.05$ ). Age, education and tenure were significantly and positively related to the ECQ, EWLQ and UWES variables $(r \geq 0.10 \leq 0.23$; small effect; $p \leq 0.01)$.

\section{Hierarchical regression analysis}

Table 2 and Table 3 summarise the hierarchical multiple regression, with ELB and EWC (ELWQ and ECQ measure) as predictors of WE. The entry of the demographic variables as the first step of the regression analysis produced a statistical model where $F(4,835)=416.80 ; p \leq 0.001$ accounts for approximately $15 \%$ of the variance in $\mathrm{WE}$, as explained by the demographic variables. The entry of people orientation, fairness, power sharing, concern for sustainability, ethical guidance, role clarification and integrity ELWQ variables explained an additional $61.9 \%$ of variations in $\mathrm{WE}$, and this change in $R^{2}$ was significant, because $F(8,831)=136.80$; $p \leq 0.001$. The addition of caring, law and codes, rules, independence and instrumental ECQ variables to the 


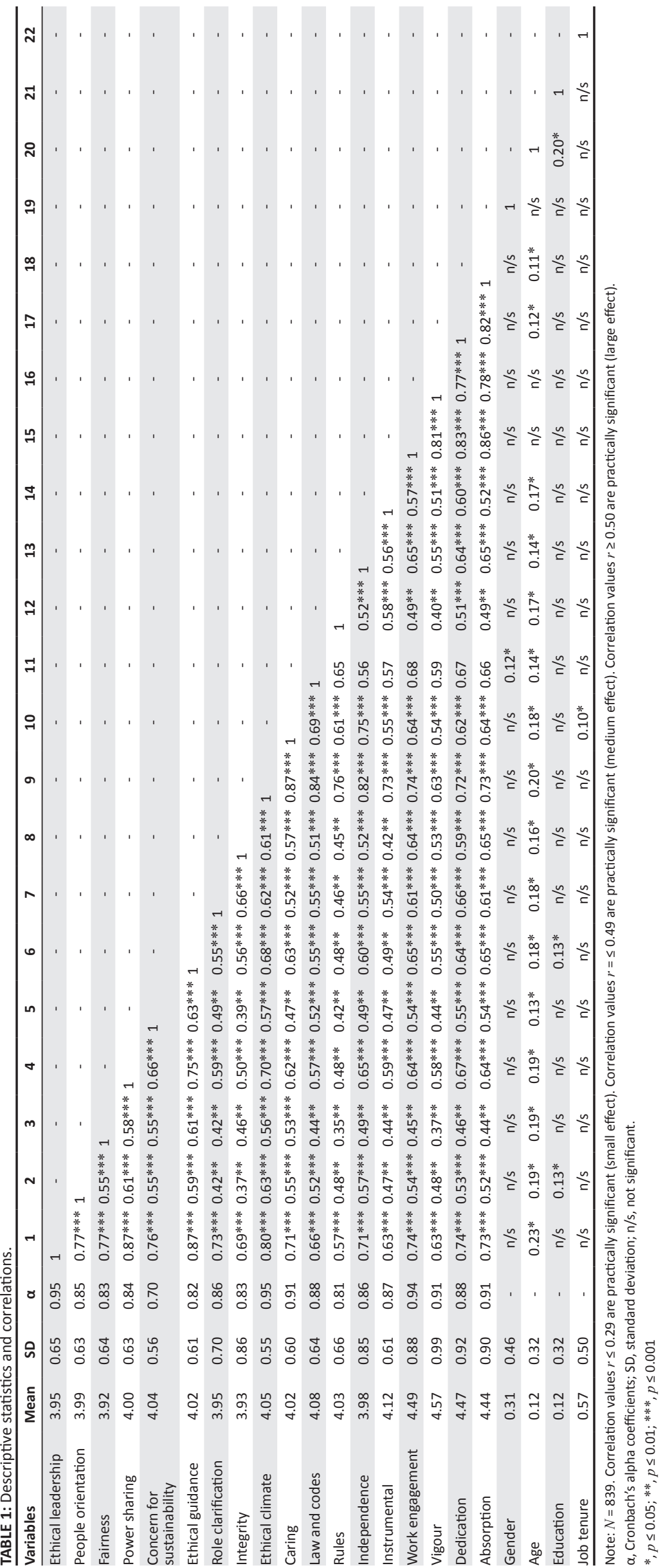


TABLE 2: Results of hierarchical regression

\begin{tabular}{|c|c|c|c|c|c|c|}
\hline \multirow[t]{2}{*}{ Predictors } & \multicolumn{2}{|c|}{ Model 1} & \multicolumn{2}{|c|}{ Model 2} & \multicolumn{2}{|c|}{ Model 3} \\
\hline & $\beta$ & $t$ & $\beta$ & $t$ & $\beta$ & $t$ \\
\hline Gender & -0.06 & -1.78 & -0.01 & -0.42 & 0.01 & 0.70 \\
\hline Age & $0.09 * *$ & 2.57 & $-0.07 * *$ & -3.06 & $-0.06 *$ & -2.82 \\
\hline Education & -0.06 & -1.54 & $-0.09 * * *$ & -4.10 & $-0.08 * * *$ & -4.12 \\
\hline Tenure & $0.08 *$ & 2.22 & 0.02 & 0.70 & 0.02 & 0.92 \\
\hline People orientation & - & - & $0.17 * * *$ & 5.81 & $0.09 * *$ & 3.25 \\
\hline Fairness & - & - & $0.10 * *$ & -3.38 & $0.12 * * *$ & 4.24 \\
\hline Power sharing & - & - & $0.24 * * *$ & 6.28 & $0.15 * * *$ & 4.12 \\
\hline Concern for sustainability & - & - & $0.08^{*}$ & 2.48 & 0.04 & 1.41 \\
\hline Ethical guidance & - & - & $0.14 * * *$ & 3.84 & $0.12 * *$ & 3.44 \\
\hline Role clarification & - & - & $0.13 * * *$ & 4.26 & 0.05 & 1.59 \\
\hline Integrity & - & - & $0.32 * * *$ & 10.43 & $0.26 * * *$ & 9.15 \\
\hline Caring & - & - & - & - & -0.01 & -0.28 \\
\hline Law and codes & - & - & - & - & $0.31 * * *$ & 9.80 \\
\hline Rules & - & - & - & - & $0.10 * * *$ & 3.55 \\
\hline Independence & - & - & - & - & $0.16 * * *$ & 4.90 \\
\hline Instrumental & - & - & - & - & $-0.07 *$ & -2.47 \\
\hline
\end{tabular}

Note: $N=839 ; *, p \leq 0.05 ; * *, p \leq 0.01 ; * * *, p \leq 0.001$

$\beta$, Standardised regression coefficient; $t$, T-statistic.

TABLE 3: Results of hierarchical regression.

\begin{tabular}{lccc}
\hline Variable & $\boldsymbol{R}$ & $\boldsymbol{R}^{2}$ & $\Delta \boldsymbol{R}^{2}$ \\
\hline Model 1 & $0.020^{*}$ & 0.015 & 0.020 \\
Model 2 & $0.624 *$ & 0.619 & 0.604 \\
Model 3 & $0.671 *$ & 0.684 & 0.066 \\
\hline
\end{tabular}

Note: $N=839 ; *, p \leq 0.05$.

$R^{2}, R$-squared; $\Delta R^{2}, R$-squared change.

regression model explained a further $68.4 \%$ of the variation in WE, and this change in $R^{2}$ was significant, because $F(12,827)=132.27 ; p \leq 0.001$. The most important predictor of WE was the ELB variable, which accounted for $61.9 \%$ of the variation in $\mathrm{WE}$. Together, the three independent variables accounted for $68.4 \%$ of the variations in WE.

\section{Discussion}

The main objective of the study was to determine whether or not EWC and ELB influence employees' level of WE in a railway organisation in the DRC. The descriptive statistics indicated that the scales of the ECQ, EWLQ and UWES were adequately internally consistent, with acceptable Cronbach's alpha values for most of the scales. This implies that the survey used was of acceptable reliability for the sample of employees participating in this study. Overall, the results showed that EWC and ELB influenced employees' level of engagement. More specifically, the caring, law and codes, rules, independence and instrumental climate significantly influenced employees' level of engagement, and that people orientation, fairness, power sharing, concern for sustainability, ethical guidance, role clarification and integrity had a positive influence on employees' WE.

In terms of the controlled variables, the literature suggests that gender, age, educational level and job tenure need to be considered in order to gain an in-depth understanding of the predictive value of EWC and ELB in raising participants' level of engagement. Age was found to correlate positively with ELB, EWC and employees' level of engagement. This implies that older employees who perceive their leaders to be fair and to treat them with respect, and who perceive their organisation to have positive policies, regulations and codes of conduct, are likely to demonstrate higher levels of engagement (Den Hartog \& Belschak 2012:38-40; Yener et al. 2012:732).

Ethical leadership behaviour was found to be related to vigour, dedication, absorption and employees' WE. In addition, a high level of integrity, power sharing and people orientation was found to be positively related to employees' level of WE. This implies that when employees perceive their leaders to practise what they preach, to treat them with dignity and to involve them in the decisionmaking process, they are more likely to be engaged in their work. These findings mirror those of Hassan and Ahmed (2011:7) and Chughtai et al. (2015:658). As a high level of fairness is significantly related to a high level of employees' WE, ethical leaders who treat followers fairly and act with integrity are likely to have a positive impact on employees' level of WE (Den Hartog \& Belschak 2012:41-42). Furthermore, a high level of role clarification, ethical guidance and concern for sustainability is significantly related to a high level of employees' WE. This implies that when employees perceive their leaders to set ethical rules and codes of conduct, engage in open communication, and protect and promote the interests of stakeholders, they are more likely to demonstrate a high level of energy and to be enthusiastic, proud and totally immersed in their work. These results can be linked to similar findings by Hassan and Ahmed (2011:7).

It was also found that a high level of caring, law and codes and rules is related to a high level of employees' WE. This implies that when employees perceive their organisation to care about their well-being and support principled decisionmaking based on external codes, and when they feel that decisions are guided by the local code of conduct, they are more likely to be engaged. This finding is in line with similar findings by Mitonga-Monga and Cilliers (2015:249). Because a high level of independence and instrumental climate is related to a high level of employees' WE, when individuals believe that they should act according to their personal moral convictions and the interests of the organisation, they are more likely to be emotionally engaged in their work. This finding is similar to that of Yener et al. (2012:733), who found EWC to relate positively with WE.

The hierarchical regression analyses indicate that employees' WE was predicted by age and tenure. This could be explained by the fact that older workers with high levels of education and tenure, who perceive their leaders as being honest and treating them with fairness, and who view their organisation as having an ethical reputation and positive working atmosphere, are likely to be more closely, emotionally and psychologically engaged in their job tasks than younger employees. These results correspond with the findings of previous studies (see James McKechnie \& Swanberg 2011:196; Haley, Mostert \& Els 2013:295; Schaufeli et al. 2006:716). 
The findings of this study indicate that WE was predicted by ELB (integrity, power sharing, people orientation, ethical guidance, role clarification, fairness and concern for sustainability). These findings are likely to be explained by the fact that when individuals perceive their leaders to behave in a consistent manner, listen to them, show concern and care, provide guidelines for ethical behaviour, clarify responsibilities, demonstrate fairness and protect stakeholders, they tend to be energetic, enthusiastic, proud and deeply immersed in their work tasks. These findings corroborate those of Changsuk et al. (2018:132); Den Hartog and Belschak (2012:46) and Demirtas et al. (2017:199), who found ethical leadership to relate to WE.

Similarly, the results suggest WE to be predicted by EWC (law and codes, independence, rules and caring). This implies that when employees perceive their organisation to have positive policies, procedures and regulations and to allow them to act in accordance with their personal moral convictions, and when they see that decision-making processes are based primarily on concern for the well-being of others, they are more likely to be energetically and enthusiastically engaged in their work. These findings confirm those of the previous studies (see Shuck \& Reio 2014:58). Similarly, Demirtas et al. (2017:199) found that if employees perceive their work environment as having positive norms, regulations and policies and if they view the leader as showing concern for them, treating them with fairness, respect and dignity, they would likely be energetic, enthusiastic, proud and happily engrossed in their work tasks. These findings corroborate those of previous studies (see Rizvi, Javed \& Siddiqui 2012:34-35).

\section{Implications for employees' well-being and performance}

The findings of this study could have important implications for both employees and organisations. The results demonstrate that nurturing EWC and ELB could contribute towards improving employees' work-related well-being and performance, both in a developing country and elsewhere. Thus, organisations may consider creating a positive ethical work environment, establishing clear ethical standards, policies, procedures, regulations and values, hiring leaders that are more ethical and providing training to existing leaders in terms of ethical conduct. Furthermore, organisations should make use of an appropriate selection battery, such as integrity tests, interviews and assessments that focus on solving ethical issues and dilemmas. In addition, organisations should recognise the importance of employees' WE and work harder to develop or improve it. An organisation that has a positive and ethical reputation and increases employees' level of engagement will not only improve the well-being and performance of its employees but also survive in the long term. Organisations that need to increase profits should enforce ethical standards, because doing so can create a fruitful synergy that could encourage employees to be engaged and contribute to the organisation's performance in the current competitive world of business. Organisations that create a positive ethical work environment, adopt an ethical management style and manage to increase WE will survive in this era of moral deficiency and ethical scandals.

Yukl (2013:340) proposes that leaders at all levels in organisations should behave in an ethical manner and strive to inculcate moral values and an ethical vision, making this visible by modelling it in the organisation and developing criteria that reward ethical behaviour, and facilitating fair and ethical solutions to problems that occur in the workplace. Taken together, our findings suggest that organisations should invest additional resources in developing ethical leaders and finding creative ways to teach and enforce ethical conduct and policies to facilitate workplace fairness. Such investment has the potential to improve organisational performance and the well-being of workers.

\section{Limitations and future research}

The study had certain limitations. The first of these was that the causal relationships between EWC, ELB and employees' WE could not be proved because of the cross-sectional design that was used. Relationships between variables were therefore interpreted rather than established. These findings need to be replicated in future research in various organisations in developing countries before conclusions can be drawn about the relationship between EWC, ELB and employees' WE. Secondly, longitudinal studies need to be conducted to examine the relationship between these variables, and how they can encourage or influence the wellbeing and performance of employees. The results of this study revealed a positive relationship between EWC, ELB and employees' WE. This could be explained by the uniqueness of the study sample.

\section{Conclusion}

The EWC variables such as law and codes, independence, rules and caring, and the ELB variables such as integrity, power sharing, people orientation, ethical guidance, role clarification, fairness and concern for sustainability seem to make the most significant contribution to employees' WE. The results highlight the fact that if these variables are present and developed or enhanced in an organisation, they could increase not only the level of employees' WE but also their well-being and performance. Developing an ethical and favourable work environment characterised by positive codes of conduct, policies, procedures and regulations, and where leaders treat others with fairness and dignity and encourage ethical behaviour will help to enhance employees' energy, enthusiasm, dedication and engagement in their work role.

\section{Acknowledgements Competing interests}

I do hereby declare that there is no conflict of interest and that this article was only submitted to Acta Commercii for review and publication. 


\section{References}

Akhtar, R., Boustani, L., Tsivrikos, D. \& Chamorro-Premuzic, T., 2015, 'The engageable personality: Personality and trait El as predictors of work engagement', Personalit and Individual Differences 73, 44-49. https://doi.org/10.1016/j.paid.2014.08.040

Babin, B.J., Boles J.S. \& Robin, D.P., 2000, 'Representing the perceived ethical work climate among marketing employees', Journal of Academic Market and Sciences 28(3), 345-358. https://doi.org/10.1177/0092070300283004

Bedi, A., Alpaslan, C.M. \& Green, S., 2015, 'A meta-analytic review of ethical leadership outcomes and moderators', Journal of Business Ethics 128(1), 1-20.

Brown, M. \& Treviño, L., 2014, 'Do role models matter? An investigation of role modelling as an antecedent of perceived ethical leadership', Journal of Business Ethics 122(4), 587-598. https://doi.org/10.1007/s10551-013-1769-0

Brown, M.E., Treviño, L.K. \& Harrison, D.A., 2005, 'Ethical leadership: A social learning perspective for construct development and testing', Organisational Behaviour \& Human Decision Processes 97(2), 117-134. https://doi.org/10.1016/j.obhdp. Human Decior
2005.03.002

Cohen, J., 1992, 'A power primer', Psychological Bulletin 112, 155-159. https://doi. org/10.1037/0033-2909.112.1.155

Chughtai, A., Byrne, M. \& Flood, B., 2015, 'Linking ethical leadership to employee wellbeing: The role of trust in supervisors', Journal of Business Ethics 128(3), 653-663. https://doi.org/10.1007/s10551-014-2126-7

Changsuk, K., Jianhong, M.A., Bartnik, R., Haney, M.H. \& Kang, M., 2018, 'Ethical leadership: An integrative review and future research agenda', Ethics \& Behaviour $28(20), 104-132$.

Cullen, J.B., Victor, B. \& Bronson, J.W., 1993, 'The ethical climate questionnaire: An assessment of its development and validity', Psychological Reports 73(2), 667-674. https://doi.org/10.2466/pr0.1993.73.2.667

DeConinck, J.B., 2010, 'The effect of organizational justice, perceived organizational support, and perceived supervisor support on marketing employees' level of trust', Journal of Business Research 63(12), 1349-1355. https://doi.org/10.1016/j. jbusres.2010.01.003

De Hoogh, A.H.B. \& Den Hartog, D.N., 2008, 'Ethical and despotic leadership, relationships with leader's social responsibility, top management team effectiveness and subordinates' optimism: A multi-method study', The Leadership Quarterly 19(3), 297-311. https://doi.org/10.1016/j.leaqua.2008.03.002

Demirtas, O., Hannah, S.T., Gok, K., Arslan, A. \& Capar, N., 2017, 'The moderated influence of ethical leadership, via meaningful work, on followers' engagement, organizational identification, and envy', Journal of Business Ethics 145(1), 183199. https://doi.org/10.1007/s10551-015-2907-7

Den Hartog, D.N. \& Belschak, F.D., 2012, 'Work engagement and Machiavellianism in the ethical leadership process', Journal of Business Ethics 107(1), 35-47. https:// doi.org/10.1007/s10551-012-1296-4

Eisenbeiß, S. \& Brodbeck, F., 2014, 'Ethical and unethical leadership: A cross-cultural and cross-sectoral analysis', Journal of Business Ethics 122(2), 343-359. https:// doi.org/10.1007/s10551-013-1740-0

Engelbrecht, A.S., Heine, G. \& Mahembe, B., 2014, “'The influence of ethical leadership on trust and work engagement": An exploratory study', South African Journal of Industrial Psychology 40(1), 1-9. https://doi.org/10.4102/sajip. v40i1.1210

Gallup, 2010, Employee engagement: What's your engagement ratio? Gallup consulting, Gallup, Washington, DC.

Hair, J.F., Black, W.C., Babin, B.J. \& Anderson, R.E., 2010, Multivariate data analysis: A global perspective, 7th edn., Pearson Education, Upper Saddle River, NJ.

Halbesleben, J.R., 2010, 'A meta-analysis of work engagement: Relationships with burnout, demands, resources, and consequences', in A.B. Bakker \& M.P. Leiter (eds.), Work engagement: $A$ handbook of essential theory and research, vol. 8 (eds.), Work engagement: A handbook of
pp. 102-117, Psychology Press, New York.

Haley, L., Mostert, K. \& Els, C., 2013, 'Burnout and work engagement for different age groups: Examining group-level differences and predictors', Journal of Psychology in Africa 23(2), 283-295. https://doi.org/10.1080/14330237.2013.10820625

Hassan, A. \& Ahmed, F., 2011. 'Authentic leadership, trust and work engagement', International Journal of Human and Social Sciences 6(3), 164-171.

James, J.B., McKechnie, S. \& Swanberg, J., 2011, 'Predicting employee engagement in an age-diverse retail workforce', Journal of Organisational Behaviour 32(2), 173196. https://doi.org/10.1002/job.681

Kacmar, K.M., Andrews, M.C., Harris, K.J. \& Tepper, B.J., 2013, 'Ethical leadership and subordinate outcomes: The mediating role of organizational politics and the moderating role of political skill', Journal of Business Ethics 115(1), 33-44. https:// doi.org/10.1007/s10551-012-1373-8

Kalshoven, K., Den Hartog, D.N. \& De Hoogh, A.H.B., 2011, 'Ethical leadership at work questionnaire (ELW): Development and validation of a multidimensional measure', The Leadership Quarterly 22(1), 51-69. https://doi.org/10.1016/j. leaqua.2010.12.007

Kalshoven, K., Den Hartog, D.N. \& De Hoogh, A.H., 2013, 'Ethical leadership and follower helping and courtesy: Moral awareness and empathic concern as moderators', Applied Psychology 62(2), 211-235. https://doi.org/10.1111/j.1464 0597.2011.00483.x

Lee, J.J.H. \& Ok, M.C.Y., 2015, 'Drivers of work engagement: An examination of core self-evaluations and psychological climate among hotel employees', International Journal of Hospitality Management 44, 84-98. https://doi.org/10.1016/j.ijhm. 2014.10.008
Lu, C.-S. \& Lin, C.-C., 2014, 'The effects of ethical leadership and ethical climate on employee ethical behaviour in the international port context', Journal of Business Ethics 124(2), 209-223. https://doi.org/10.1007/s10551-013-1868-y

Lu, X., Xie, B. \& Guo, Y., 2018, 'The trickle-down of work engagement from leader to follower: The role of optimism and self-efficacy', Journal of Business Research 84 186-195. https://doi.org/10.1016/j.jbusres.2017.11.014

Martin, K.D. \& Cullen, J.B., 2006, 'Continuities and extension of ethical climate theory: A meta-analysis review', Journal of Business Ethics 90(4), 293-306. https://doi. org/10.1007/s10551-006-9084-7

Mayer, D.M., Kuenzi, M. \& Greenbaum, R.L., 2010, 'Examining the link between ethical leadership and employee misconduct: The mediating role of ethical climate', Journal of Business Ethics 95(1), 7-16. https://doi.org/10.1007/s10551-011-0794-0

Mayer, D.M., Nurmohamed, S., Treviño, L.K., Shapiro, D.L. \& Schminke, M., 2013 'Encouraging employees to report unethical conduct internally: It takes a village' Organizational Behaviour and Human Decision Processes 121(1), 89-103. https:// doi.org/10.1016/j.obhdp.2013.01.002

Mitonga-Monga, J. \& Cilliers, F., 2015, 'Ethics culture and ethics climate in relation to employee engagement in a developing country setting', Journal of Psychology in Africa 25(3), 242-249. https://doi.org/10.1080/14330237.2015.1065059

Mitonga-Monga, J. \& Cilliers, F., 2016, 'Perceived ethical leadership: Its moderating influence on employees' organisational commitment and organisational citizenship behaviours', Journal of Psychology in Africa 26(1), 35-42. https://doi.org/ 10.1080/14330237.2015.1124608

Mitonga-Monga, J. \& Flotman, A.P., 2017, 'Gender and work ethics culture as predictors of employees' organisational commitment', Journal of Contemporary Management 14(1), 270-290.

Mitonga-Monga, J., Flotman, A.P. \& Cilliers, F., 2016, 'Workplace ethics culture and work engagement: The mediating effect of ethical leadership in a developing world context', Journal of Psychology in Africa 26(4), 326-333. https://doi.org/10.1080/1 4330237.2016.1208928

Mitonga-Monga, J., 2018, 'Ethical climate influences on employee commitment through job satisfaction in a transport sector industry', Journal of Psychology in Africa 28(1), 15-20. https://doi.org/10.1080/14330237.2018.1426710

Obicci, P.A., 2015, 'Influence of extrinsic and intrinsic rewards on employee engagement (empirical study in public sector of Uganda)', Management Studies and Economic System 2(1), 59-70. https://doi.org/10.12816/0018083

Rich, B.L., Lepine, J.A. \& Crawford, E.R., 2010, 'Job engagement: Antecedents and effects on job performance', Academy of Management Journal 53(3), 617-635. https://doi.org/10.5465/amj.2010.51468988

Rizvi, L., Javed, O.D. \& Siddiqui, K.A., 2012, 'Examining the impact of job security, organizational climate and engagement on motivation level of employees at IMC PVT LTD', European Journal of Business and Management 4(9), 27-35.

Saks, A.M., 2006, 'Antecedents and consequences of employee engagement', Journal of Management Psychology 27(7), 600-619. https://doi.org/10.1108/ 02683940610690169

Schaufeli, W.B., 2013, 'What is engagement?' in C. Truss, K. Alfes, R. Delbridge, A. Shantz $\&$ E. Soane (eds.), Employee engagement in theory and practice, pp. 15-35, Routledge, London.

Schaufeli, W.B., Bakker, A.B. \& Salanova, M., 2006, “'The measurement of work engagement with a short questionnaire": A cross-national study', Educational and Psychological Measurement 66(4), 701-716. https://doi.org/10.1177/ 0013164405282471

Schaufeli, W.B., Bakker, A.B. \& Van Rhenen, W., 2009, 'How changes in job demands and resources predict burnout, work engagement, and sickness absenteeism' Journal of Organizational Behaviour 30, 893-917. https://doi.org/10.1002/ job.595

Schaufeli, W.B., Salanova, M., Gonzàlez-Roma, V. \& Bakker, B.A., 2002, “"The measurement of engagement and burnout": Two sample confirmatory analytic approaches', Journal of Happiness Studies 3(1), 71-92. https://doi.org/ 10.1023/A:1015630930326

Shuck, B. \& Reio, T.G., 2014, 'Employee engagement and well-being: A moderation model and implications for practice', Journal of Leadership \& Organizational Studies 21(1), 43-58. https://doi.org/10.1177/1548051813494240

Schulman, M., 2002, How we become moral. Handbook of positive psychology, Oxford University Press, New York, pp. 499-512.

Thaw, Y.Y., Dominic, P.D.D. \& Mahmood, A.K., 2012, 'The factors associating consumers' trust in e-commerce transactions: Malaysian consumers' perspectives', International Journal of Business Innovation and Research 6(2), 238-257. https:// International Journal of Business Innova
doi.org/10.1504/IJBIR.2012.045639

Treviño, L.K., Den Nieuwenboer, N.A. \& Kish-Gephart, J.J., 2014, '(Un) ethical behaviour in organizations', Annual Review of Psychology 65, 635-660. https:// doi.org/10.1146/annurev-psych-113011-143745

Tu, Y., Lu, X. \& Yu, Y., 2017, 'Supervisors' ethical leadership and employee job satisfaction: A social cognitive perspective', Journal of Happiness Studies 18(1) 229-245. https://doi.org/10.1007/s10902-016-9725-1

Victor, B. \& Cullen, J.B., 1988, 'The organisational bases of ethical work climates', Administrative Sciences Quarterly 33(1), 101-125. https://doi.org/10.2307/ 2392857

Yener, M., Yaldiran, M. \& Ergun, S., 2012, 'The effects of ethical climate on work engagement', Procedure Social \& Behavioural Sciences 58(12), 724-733. https:// doi.org/10.1016/j.sbspro.2012.09.1050

Yukl, G., 2013, Leadership in organizations, Pearson, Upper Saddle River, NJ. 